\title{
The spectacular presentation of orf disease
}

\section{Funda Tamer ${ }^{1}$, Mehmet Eren Yuksel ${ }^{2}$}

${ }^{1}$ Department of Dermatology, Ufuk University School of Medicine, Ankara, Turkey, ${ }^{2}$ Department of General Surgery, Aksaray University School of Medicine, Aksaray, Turkey

Corresponding author: Dr. Funda Tamer, E-mail: fundatmr@yahoo.com

\begin{abstract}
Orf is a viral zoonotic skin disorder which is also called ecthyma contagiosum. The disease primarily affects sheep and goats, however it can be transmitted to humans through close contact with infected animals. Orf presents with characteristic skin lesions and the diagnosis of orf is usually made based on its clinical features. Hereby, we present a 21-year-old female patient with orf disease with a characteristic clinical lesion on her hand.
\end{abstract}

Key words: Contagious; Ecthyma; Orf; Skin; Viral

\section{INTRODUCTION}

Orf is an infectious disease which spreads by direct contact with sheep and goats [1]. The etiopathogenic agent is Orf virus. It belongs to the Parapoxvirus genus of the Poxviridae family. Orf virus is usually transmitted through the breaks and abrasions on the skin. The disease is generally localised to the hands. Systemic involvement has not been previously reported [2]. Farmers, butchers, sheep shearers and veterinarians are prone to disease [3]. Orf has a characteristic clinical pattern including inflamed macules, papules, vesicles, nodules, verrucous lesions and scar tissue. The incubation period can vary from 3 to 5 days. The disease first appears as erythematous macules which evolve to papules with a target appearance in 7 to 14 days. Afterwards, the lesions become nodular and vesicular which ulcerate in 2-3 weeks. The lesions are usually asymptomatic, however secondary infections can lead to pain and discomfort. Orf disease usually heals by itself completely in 4-8 weeks [4].

\section{CASE REPORT}

A 21-year-old Caucasian female patient was admitted for further clinical evaluation of the lesion on her hand. The lesion first appeared as an erythematous macule and it increased in size gradually within the last 2 weeks. The lesion was asymptomatic. The patient whose father was a farmer was living in a rural area. The patient stated that she helped her family to raise sheep. The medical history was unremarkable. Dermatological examination revealed a grey-black colored plaque with erythematous-purple colored sharp borders and ulcerated-crusted area at the center on the third finger of her left hand (Fig. 1). The lesion had concentric zones and a targetoid appearance. We made the diagnosis of orf based on its clinical features and physical examination. The patient was started on topical mupirocin ointment to prevent secondary bacterial infections. The orf lesion healed completely after 6 weeks.

\section{DISCUSSION}

Orf is a self-limited zoonotic infection which can be transmitted to people by direct/indirect contact with infected animals and animal products [5]. Orf usually presents as a solitary lesion on the hand. However, multiple lesions have also been described in the medical literature [6]. The diagnosis of orf is usually made based on its clinical features and the exposure history of the patient [7]. In suspicious cases, a skin biopsy and polymerase chain reaction may be performed [8]. No specific therapy is necessary for orf. However, 


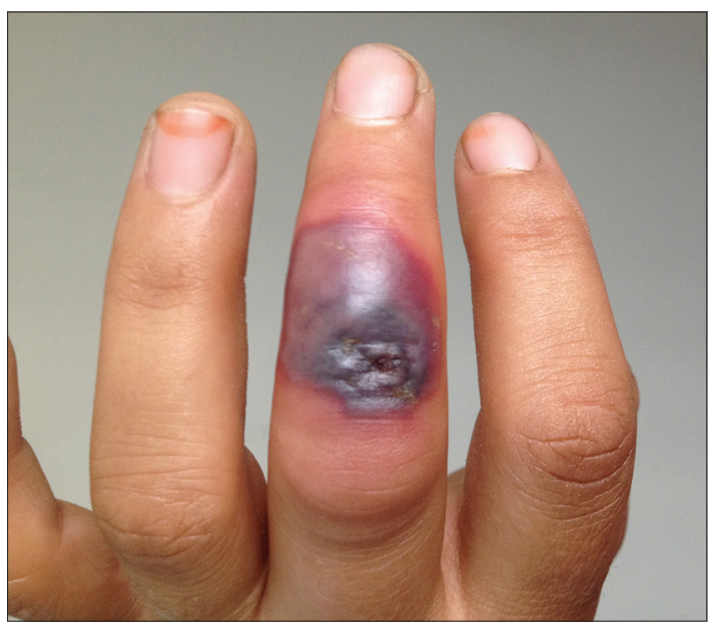

Figure 1: A targetoid plaque with erythematous-purple colored borders and grey-black colored, crusted center on the extansor surface of the third finger of the left hand.

the disease can easily be misdiagnosed as a bacterial infection or a neoplasm [5]. In immunocompromised patients, persistent lesions may require excision. It has been suggested that 1 -week topical imiquimod therapy accelerated the healing of the lesions [9]. Geerinck et al. described a renal transplant patient with a growing orf lesion who was succesfully treated with topical cidofovir [10]. Orf has a benign course, however the lesions may reoccur in immunosuppressed patients [6]. Moreover, Duchateau et al. described autoinoculation with Orf virus in a patient who took azathioprine because of Crohn's disease [8]. Systemic symptoms do not occur, however, complications including fever, lymphangitis and lymphadenopathy have been reported. Furthermore, erythema multiforme and autoimmune bullous disease may be associated with orf [4].

\section{CONCLUSION}

Hereby, we present a case of orf disease with typical clinical course and appearance. Despite its rarity, orf disease should be included in the differential diagnosis of erythematous nodules, targetoid or crusted skin lesions of the hands.

\section{REFERENCES}

1. Alian S, Ahangarkani F, Arabsheybani S. A case of orf disease complicated with erythema multiforme and bullous pemphigoidlike eruptions. Case Rep Infect Dis. 2015;2015:105484.

2. Fleming SB, Wise LM, Mercer AA. Molecular genetic analysis of orf virus: a poxvirus that has adapted to skin. Viruses. 2015;7:1505-39.

3. Meier R, Sommacal A, Stahel A, Grünert J, Hoffmann M. Orf - an orphan disease? JRSM Open. 2015;6:2054270415593718.

4. Maor D, Yu LL, Brand R. A case of orf disease in a patient with scleroderma. JAAD Case Rep. 2017;3:155-7.

5. Centers for Disease Control and Prevention (CDC). Antibodies cross-reactive to influenza A (H3N2) variant virus and impact of 2010-11 seasonal influenza vaccine on cross-reactive antibodiesUnited States. MMWR Morb Mortal Wkly Rep. 2012;61:237-41.

6. Turan E, Yesilova Y, Ucmak D. A case of orf (ecthyma contagiosum) with multiple lesions. J Pak Med Assoc. 2013;63:786-7.

7. Koufakis T, Katsaitis P, Gabranis I. Orf disease: a report of a case. Braz J Infect Dis. 2014;18:568-9.

8. Duchateau NC, Aerts O, Lambert J. Autoinoculation with Orf virus (ecthyma contagiosum). Int J Dermatol. 2014;53:e60-2.

9. Al-Qattan MM, Helmi AA. Chronic hand infections. J Hand Surg Am. 2014;39:1636-45.

10. Geerinck K, Lukito G, Snoeck R, De Vos R, De Clercq E, Vanrenterghem $\mathrm{Y}$, et al. A case of human orf in an immunocompromised patient treated successfully with cidofovir cream. J Med Virol. 2001;64:543-9.

Copyright by Funda Tamer, et al. This is an open-access article distributed under the terms of the Creative Commons Attribution License, which permits unrestricted use, distribution, and reproduction in any medium, provided the original author and source are credited.

Source of Support: Nil, Conflict of Interest: None declared. 